\title{
Soil Erosion, Policy and Managements in China Coastal Zone
}

\author{
Qingshui Lu ${ }^{\mathrm{a}}$, Zhiqiang Gao ${ }^{\mathrm{a}}$, Qiaochen ${ }^{\mathrm{b}}$, Jicai Ning ${ }^{\mathrm{a}}$, Runhe Shi ${ }^{\mathrm{c}}$, Wei Gao ${ }^{\mathrm{c}}$
}

${ }^{a}$ Key Laboratory of Coastal Zone Environmental Processes, Yantai Institute of Coastal Zone Research, CAS, Yantai, 264003, China; ${ }^{\mathrm{b}}$ College of Geological Sciences \& Engineering, Shandong University of Science and Technology, Qingdao City, 266510, China; ${ }^{\mathrm{C} U S D A}$ UV-B Monitoring and Research Program and Center of Remote Sensing and Modeling for Agricultural Sustainability, Natural Resource Ecology Laboratory,Colorado State University, Fort Collins, CO, USA

\begin{abstract}
The coastal zone is very important in the world. China coastal zone was granted the first priority of developing economy in the late 1980s. Since then, high population density and rapid economic development hace caused intensive changes of LUCC in this zone. Those changes have lead to land degradation. Besides, China governments launched series of projects and policy to improve such problems. Those will inevitably cause to diverse spatial dynamics of land degradtion. However, the state of land degradation in certain time is still unknown. Soil erosion is an important indicator of land degradation. Therefore, we use RS images, RUSLE model to anlyze the spatial pattern of soil erosion for 2000. By spatial analysis, we found that soil erosion in China coastal zone is not serious. Widespread soil erosion is only occurred on coastal zones in Shandong, Hainan and werstern Guangdong Province. Although rainfall eosivity factor(R) is higher in southern coastal zone, erosion tends to occur on the slopes with lower LS values in northern coastal zone than southern coastal zone. Goevernments have enforced some policy to reduce the extent of soil erosion by conversion of farmland to woodland and barren mountains to woodland. But the difference between southern and northern coastal zone is still not realized. To improve soil eorosion in those areas, we should let governments put more funds to increase vegetation cover in north. Such study will provide helpful suggestions for governments to prevent soil erosion in coastal zone.
\end{abstract}

Keywords: Coastal zone; RUSLE; soil erosion; driver factors

\section{Introduction}

The coastal zone is very important in the world. It is estimated that the majority of the world's population habitats in the costal zone within only 5\% of area of the world (Inman \& Brush, 1973; Shi et al., 2001). Coastal zone was granted the first priority of developing economy in the late 1980s. Since then, economy in this zone began to increase rapidly, and land use and land cover(LUCC) in China coastal zone are facing series of dynamic chanlenges.

Rapid economic and social developments have caused changes in territory sysytems of coastal zone. Over the past decades, the area of coastal wetland had been reduced (Lin et al ., 2007; Chen \& Chen, 2002), lot of farmland had been replaced by urban and rurual settlement ( Liu et al., 2005; Long et al., Lu et al.,2011), oil fields and gold mines were exoplored and high percentage of tidal-flat was reclaimed (Zhao et al., 2004; Shen et al., 2006; Bi et al., 2011). It is well known that coastal zone is very vulnarable because it is located between oceans and continents and affected by many factors (Sterr, 2008; Dolan \& Walker, 2006). Such intensive changes of LUCC will inevitably lead to land degradation.

Remote Sensing and Modeling of Ecosystems for Sustainability X, edited by Wei Gao,

Thomas J. Jackson, Jinnian Wang, Ni-Bin Chang, Proc. of SPIE Vol. 8869, 886919

(C) 2013 SPIE · CCC code: 0277-786X/13/\$18 · doi: 10.1117/12.2021638

Proc. of SPIE Vol. $8869886919-1$ 
Besides, China government launched the Shelter Forest Project to peotect land from degradation in coastal zone in 1970s (Ni, 2000). Lots of coastal shelter forest have been constructed along the coastline. China government also issued series of policy to reduce the risk of vulnerability in coastal zone. Local governemnts has made a number of coastal zone land use plannings to optimize the composition of land use, and integrated watershed management was also executed in coastal catchments (Wu et al., 2012). Those will inevitably lead to spatial dynamics of land degradtion. However, the state of land degradation in certain time is still unknown. Soil loss is an important indicator of land degradtion. Therefore, our objectives in this article is to analyze the spatial pattern of soil erosion, understand their drivers and provide suggests for improving current states based on current policy.

\section{Study area and methods}

\subsection{Study area}

Study area is located between $41^{\circ} 19^{\prime}-18^{\circ} 4^{\prime} \mathrm{N}$ and $108^{\circ} 5^{\prime}-122^{\circ} 54^{\prime} \mathrm{E}$, with an area of about $96727.8 \mathrm{Km}^{2}$ (Fig.1). The continental coastline is $18000 \mathrm{~km}$ long. It is administrated by eight provinces, one autonomous region, and three municipal cities. The climates are composed of the temperate climate, warm temperate climate, subtropical climate and tropical climate from north to south along the coastline. Average annual precipitation ranges from $600 \mathrm{~mm}$ to $1600 \mathrm{~mm}$.

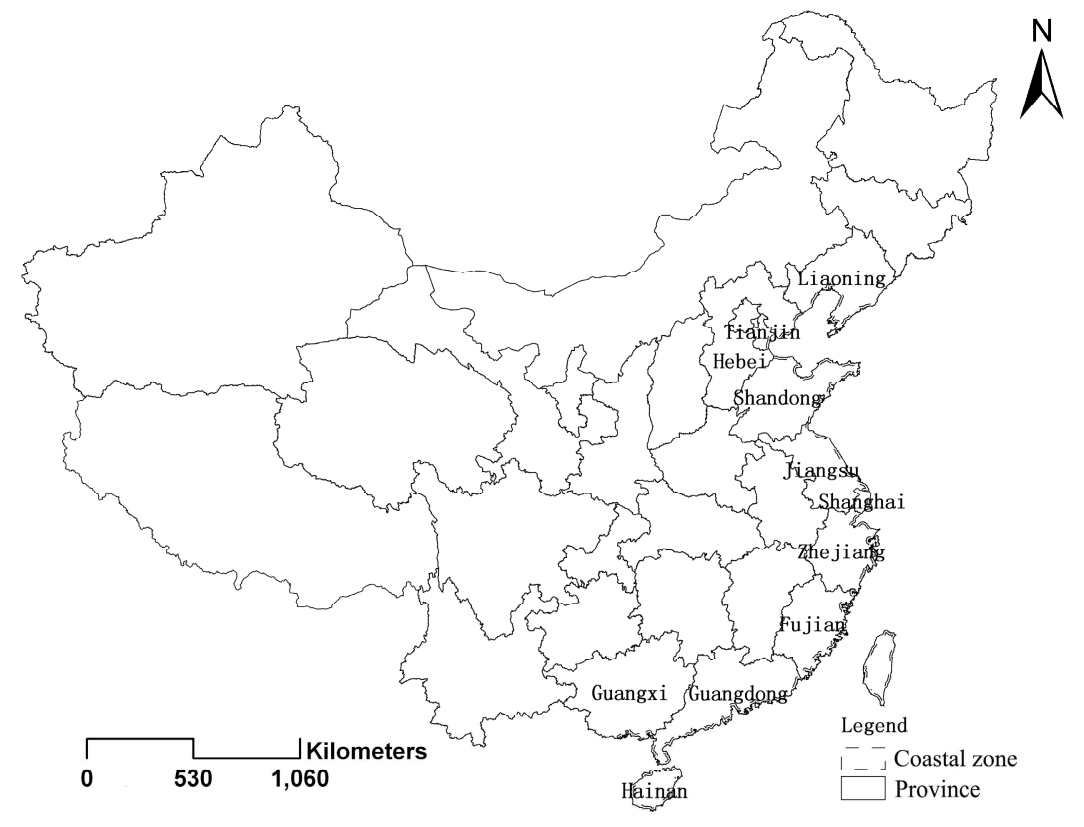

Fig.1 Location of study area

\subsection{Method}

\subsubsection{RUSLE Model}

The universal soil loss equation was used to calculate the average annual soil loss and its spatial distribution on coastal zone of China. The advantage of the model is that the model has been widely applied in many researches and can be used to access soil loss at large scale with high accuracy. In the RUSLE, the mean annual soil erosion is expressed as a function of six erosion factors:

$$
A=R \bullet K \bullet L \bullet S \bullet C \bullet P
$$

Where $A$ is average annual soil loss rate (t ha-1year-1), $\mathrm{R}$ is rainfall erosive factor $\left(\mathrm{MJ} \mathrm{mm} \mathrm{ha}^{-1} \mathrm{~h}^{-1} \mathrm{year}^{-1}\right), \mathrm{K}$ is soil 
erodibility factor ( $\mathrm{t} \mathrm{ha} \mathrm{h} \mathrm{ha-1} \mathrm{MJ}^{-1} \mathrm{~mm}^{-1}$ ), LS is topographic factor, $\mathrm{C}$ is crop management factor, and $\mathrm{P}$ is conservation supporting practice factor. In this study, average annual soil loss was estimated by multiplying five digital parameter layers(R, K, LS, C, P) in raster format. Computing methods of factors R, C and P were modified according to Chinese Researchers.

\subsubsection{Rainfall Erosivity(R)}

Rainfall data of 20 years (1981-2000) in 162 meteorological observation stations across the research area from State Meteorological Bureau was used for calculating R-factor. The area has no record of rainfall intensity as a result daily rainfall data were used to calculate R-factor annually using the following relationship developed by Zhang et al. (2002):

$$
M=\alpha \sum_{j=1}^{k}\left(P_{j}\right)^{\beta}
$$

Where, $\mathrm{M}$ is half month rainfall erosivity factor in $\mathrm{MJ} \mathrm{mm} \mathrm{ha}^{-1} \mathrm{~h}^{-1}$ year ${ }^{-1}$. Each month was divided into two sections by each month's fifteenth day, the first section was as a half month, and the left was as another half month. A whole year was divided into 24 sections by this method. $\mathrm{K}$ is number of days for corresponding half month, $P_{j}$ is the erosivity rainfall for day $\mathrm{j}$, and the daily rainfall must be above $12 \mathrm{~mm}$, or calculated as zero. Threshold value $12 \mathrm{~mm}$ was based on China erosivity rainfall regulations (Xie et al.,2000). $\alpha, \beta$ are model parameters calculated according to the following relationship:

$$
\beta=0.8363+\frac{18.144}{P_{d 12}}+\frac{24.455}{P_{y 12}} \quad \alpha=21.586 \beta^{-7.1891}
$$

Where, $P_{d 12}$ is average daily rainfall that daily rainfall is above $12 \mathrm{~mm}, P_{y / 2}$ is average annual rainfall that daily rainfall is above $12 \mathrm{~mm}$. In this study, daily rainfall data from 1980 to 2000 was used to calculate $\alpha, \beta$ with formula (3), then to calculate each half month rainfall erosivity with formula (2) within a year for the whole period for each station. Annual rainfall erosivity of each station was gotten by mean method, and then spatial distribution of annual rainfall erosivity was gotten by interpolation with Anuspline.

\subsubsection{Soil Erodibility Factor (K)}

1:1 million Chinese Soil Data from Data Center of Chinese Academy of Sciences was used to calculate soil erodibility(1995). Soil erodibility was calculating with the following formula (Wischmeier et al., 1978; Renard et al., 1997):

$$
K=7.954 \times\left\{0.0017+0.0494 \times \exp \left[-\frac{1}{2}\left(\frac{\log \left(D_{g}\right)+1.675}{0.6986}\right)^{2}\right]\right\}
$$

Where, $D_{g}$ represents average particle size parameter.

\subsubsection{Topographic factor (LS)}

The data used to calculate LS was ASTER DEM from NASA. The L-factor was calculated based on the equation developed by Van Remortel et al.(2001).

When slopes $\theta<5^{\circ}$, LS was calculated with the following equation: 


$$
L S=\left(\frac{\lambda}{22.13}\right)^{m}(10.8 \sin \theta+0.03)
$$

When slopes $5^{\circ} \leq \theta<10^{\circ}$, LS was calculated with the following equation:

$$
L S=\left(\frac{\lambda}{22.13}\right)^{m}(16.8 \sin \theta-0.96)
$$

When slopes $\theta \geq 10^{\circ}$, LS was calculated with the following equation:

$$
L S=\left(\frac{\lambda}{22.13}\right)^{m}(21.91 \sin \theta-0.96)
$$

Where, when $\theta<0.5^{\circ}, \mathrm{m}=0.2$; when $0.5^{\circ} \leq \theta<1.5^{\circ}, \mathrm{m}=0.3$; when $1.5^{\circ} \leq \theta<3^{\circ}, \mathrm{m}=0.4$; when $3^{\circ} \leq \theta<5^{\circ}, \mathrm{m}=0.5 ; \lambda$ is slope length.

\subsubsection{Vegetation Cover and Crop Management}

LUCC in 2000 gotten from TM images with visual interpretation and Spot NDVI with a time resolution of 15 days in 2000 was used to calculate vegetation and crop management factor. $\mathrm{C}$ value for forest, grassland and farmland was divided into canopy cover factor $C_{c}$ and the surface cover factor $C_{s}$. C value was calculated with the following equations developed by Liu et al.(2010):

$$
C=C_{c} \cdot C_{s}
$$

$\mathrm{C}_{\mathrm{c}}$ factor for farmland and grassland was calculated with the following equation:

$$
C_{c}=1-\left(0.01 V_{c}+0.0859\right) e^{-0.0033 h}
$$

$\mathrm{C}_{\mathrm{c}}$ factor for forest was calculated with the following equation:

$$
C_{c}=0.5262 * e^{-0.05 V_{c}}
$$

$\mathrm{C}_{\mathrm{s}}$ factor was calculated based on the following equation:

$$
C_{s}=1.029 e^{-0.0235 V_{c}}
$$

Where, $\mathrm{V}_{\mathrm{c}}$ is vegetation coverage $(\%), \mathrm{h}$ is canopy height $(\mathrm{cm})$.

Vegetation coverage was calculated with the following equation according to Wu et al.(2009):

$$
f_{v}=\frac{N D V I-N D V I_{\min }}{N D V I_{\max }-N D V I_{\min }}
$$

\subsubsection{Conversation Practice Factor (P)}

All farmland has conservation practices in this area. The main conservation practice for sloping farmland is contour-farmed terrace and the main conservation practice for paddy field is building ridge. Forest and grassland have no conservation practice. The values for P-factor were assigned based on the values recommended by Wischmeier and 
Smith ( 1978), Renard et al.( 1997) and Xu et al.(2011). Detailed values are given in table 1.

Table 1 P Values for Land use and Land Cover Types

\begin{tabular}{llllllll}
\hline LUCC & Paddy Field & Dry Farm & Forest & Grassland & Water\&Swamp & City\&Village & $\begin{array}{l}\text { Bare land and } \\
\text { Saline-Alkali Soil }\end{array}$ \\
\hline$P$ Value & 0.01 & $0.5-0.9$ & 1 & 1 & 0 & 0 & 1 \\
\hline
\end{tabular}

\section{Result and analysis}

\subsection{Asssessment of model accuracy}

Fiver factors of RUSLE model were multiplied to get the spatial distribution of average annual soil loss for 2000 . Average annual soil losses were grouped into different classes as suggested by the Ministry of Water Resources of China (2008)(Fig.2). Fig. 2 shows that there is no obvious erosion in middle-low reaches of Yangtze River Plain, which is located within Jiangsu Province and Zhejiang Province in 2000. In Shandong Province, high percentage of hilly area was covered with high erosion. Severe erosion ocasionaly occurred on hilly areas in Fujian, Guangdong and Guangxi. Such spatial distribution of soil erosion was compared with standards for classification and gradation of soil erosion(The Ministry of Water Resources of China, 2008)(Table 2).We found out that our results and the standards have the similar pattern. Therefore, our results for coastal zone are very credible.

Table 2 Erosion classes in Coastal provinces of China

\begin{tabular}{ll}
\hline REGIONS & EROSION CLASSES \\
\hline Middle and Lower Yangtze River Plain & No obvious soil loss \\
\hline $\begin{array}{c}\text { Guangdong, Guangxi and Fujian } \\
\text { Mountainous area in Shandong }\end{array}$ & Occasionally soil loss in areas with high altitude \\
\hline
\end{tabular}

(According to The Ministry of Water Resources of China, 2008)

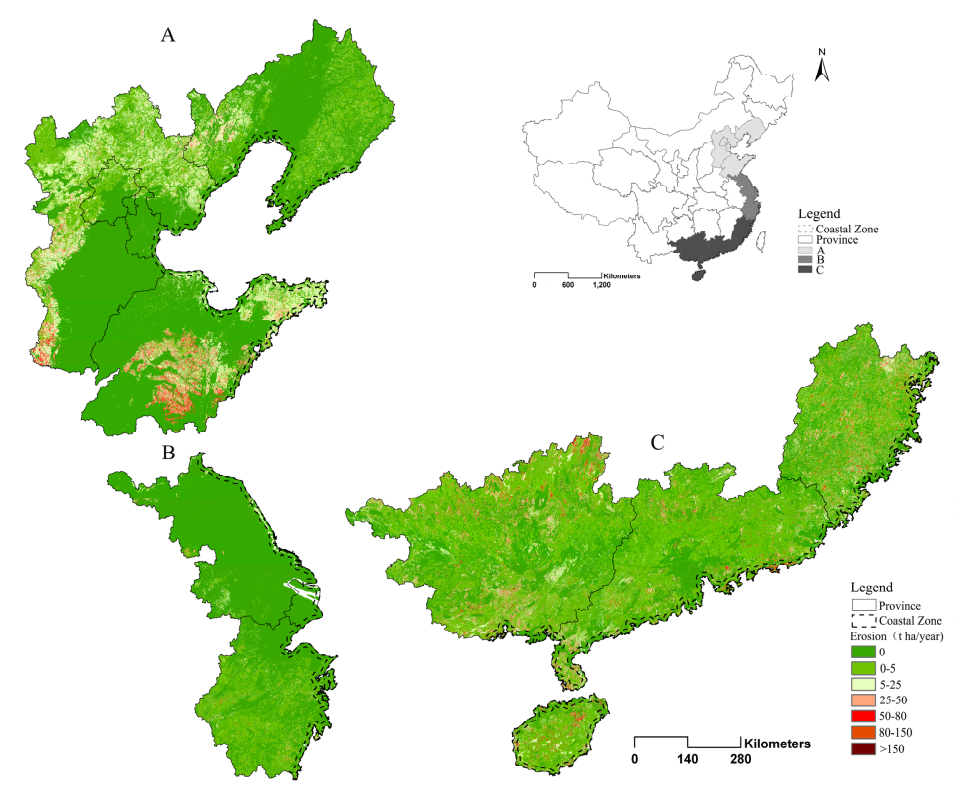

Fig.2 Soil erosion on study area: A-Liaoning,Hebei,Tianjin,Shandong; B-Jiangsu,Zhejiang; C-Fujian,Guangdong,Guangxi,Hainan 


\subsection{Spatial pattern of erosion}

Fig. 3 shows that soil erosion in China coastal zone is not very serious and widespread erosion only occurs on the coastal zone of north Hebei, Shandong, western Guangdong, Hainan. Major erosion class is moderate erosion. Severe erosion only occasionaly occurs on some areas in the coastal zone of south China.

\subsubsection{Soil erosion on cosatal areas aroud Bohai Sea}

Most of coastal zone in Liaoning Province is covered by farmland and only a small amount of land is covered by forest. Topograph in most of coastal zone is the plain. In the plain, LS value closes to zero, the parameter of soil particles is relatively low. All farmland has applied conservation pratices. Therefore, most of coastal zone has no soil erosion. Moderate erosion is occasionally occurred on the hilly and mountainous areas in the parts that extened to Shandong Province and are near to Hebei Province, and the average rate of soil loss rangs from $5 \mathrm{t}$ ha/year to $25 \mathrm{t}$ ha/year.

Topograph in coastal zone of northern Hebei Province is mountains, and the main land use type is farmland. Moderate soil erosion occasionaly occurs on this area. In the coastal zone of southern Hebei Province and Tianjian City is Northern China Plain. The toporagh is very plat. Erosion is only occasionally ocurred on the slight upland.

Soil erosion expansively distributes on the coasatl zone in Shandong Province. In northen part of Shandong's coastal zone, topograph is composed of plains and slight uplands. The main land use type is bare land and shallows. Moderate soil erosion is the main erosion class, and average annual soil loss is $5-25 \mathrm{t}$ ha/year. In southern coastal zone of Shandong Province, topograph is mainly composed of hills. Plains and Mountains are occasionly occurred on some areas. Most of coastal zone is used as farmland. Most of coastal zone is under moderate soil erosion.

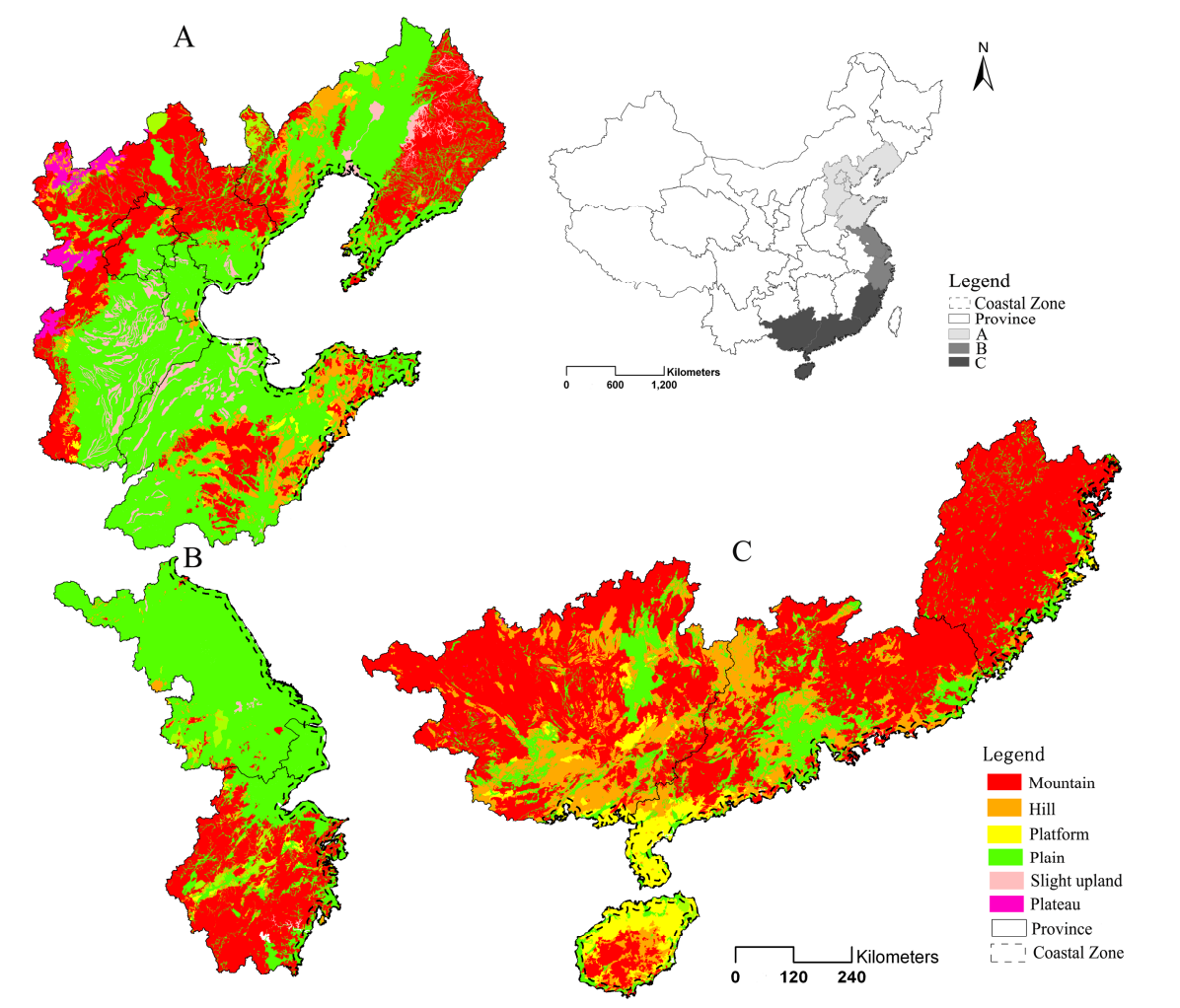

Fig.3 Landscape in Study area: A-Liaoning,Hebei,Tianjin,Shandong; B-Jiangsu,Zhejiang;

C-Fujian, Guangdong,Guangxi,Hainan 


\subsubsection{Erosion on coastal zone of Shanghai, Jiangsu and Zhejiang Provinces}

The plain extends along the coastline of Jiangsu Province. Middle part of this coastal zone is shallows and others are mainly used as dryland or wet field. Most of middle coastal zone of Jiangsu Province is under moderate erosion class, and the average annual soil loss rangs from $5 \mathrm{t}$ ha/year to $25 \mathrm{t}$ ha/year. Soil erosion in Shanghai and Zhejiang's coastal zone is not obvious. Althogh large amount of area in Zhejiang's coastal zone is mountains, only slight erosion occasionaly occurs.

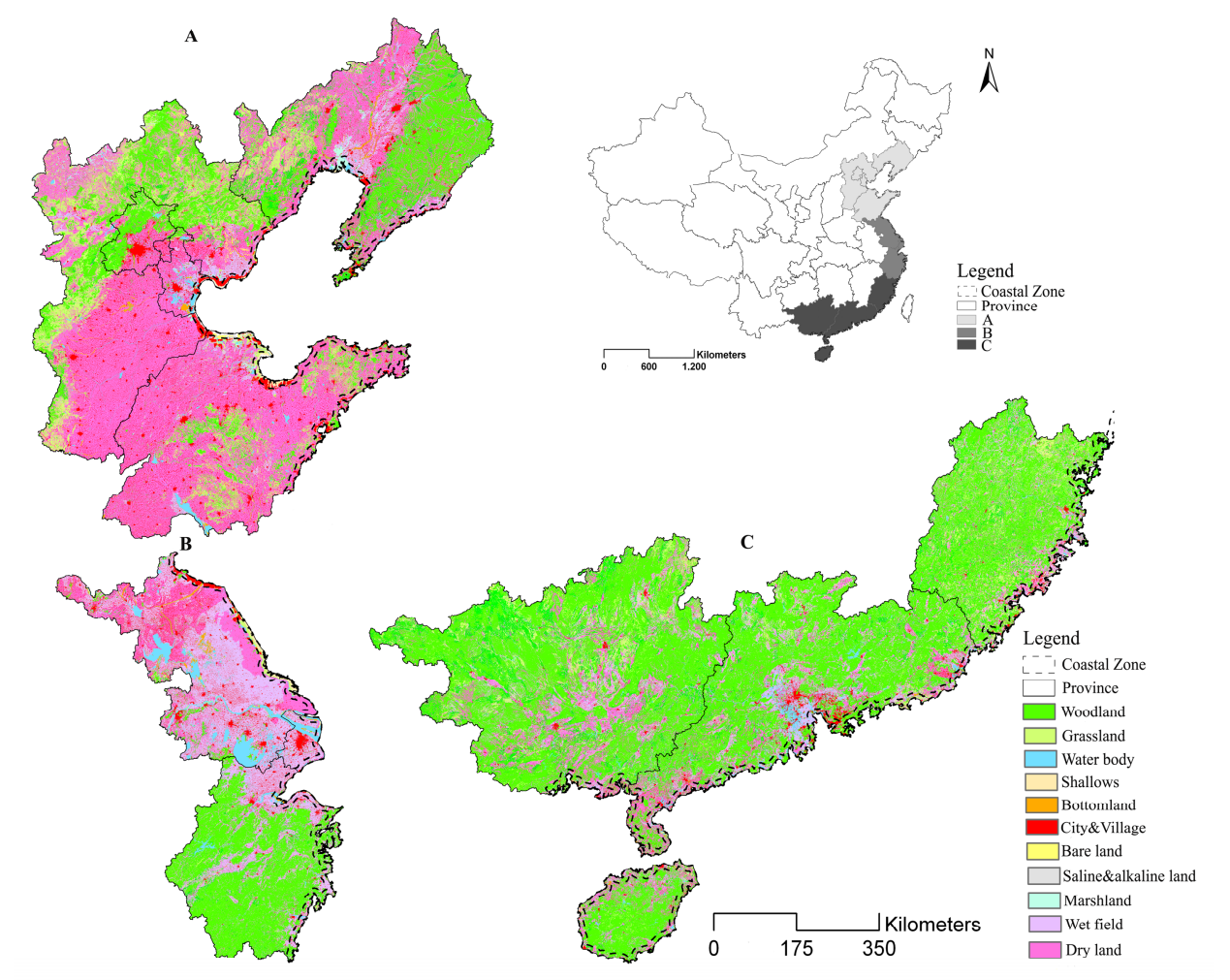

Fig.4 Land use in coastal zone of China: A-Liaoning,Hebei,Tianjin,Shandong; B-Jiangsu,Zhejiang;

\section{C-Fujian,Guangdong,Guangxi,Hainan}

\subsubsection{Soil Erosion on coastal zone of Fujian, Guangdong and Guangxi, Hainan}

Most of plains in Fujian is distributed in its middle coastal zone and the main landuse types are wet field and dry land. Due to relative flat topograph, soil erosion is not obvious. Northern coastal zone, that is near to Zhejiang, mainly consists of mountains and is covered by forest. High vegetation cover and steep slopes of mountain areas cause to slight soil erosion. Southern coastal zone of Fujian has the same topograph as northern coastal zone of Fujian, and slight erosion expansively extends along the coastline.

In Guangdong Province, coastal zone plains are mainly distributed in the middle and northern coastal zones, coastal platform is in the area that extends to Hainan Province, and other coastal zones are mainly composed of hills and mountains. Most of coastal zone platform is used as farmland and under the moderate and severe erosion classes. Other severe erosion occasionaly occurred on mountains due to forest damage. There is no obvious erosion in plains.

Terrain in Hainan coastal zone is composed of platform, mountains and plains. Mountains only distrbute in southern coastal zone. Soil erosion is expansively distributed on the mountains and platforms. The main erosion classes include 
moderate and severe erosion class. The coastal zone in Guangxi is mainly composed of platforms and hills. Soil eorion only occur on western hills and mountains. Soil erosion on eastern coastal zone of Guangxi is not obvious.

\subsection{Factors and erosion}

According to erosion function, soil erosion was mainly caused by rainfall erosivity factor(R), soil erodibility factor $(\mathrm{K})$, topographic factor (LS), crop management factor(C), and conservation supporting practice factor (P). Spatial patterns of those factors were compared with the pattern of soil erosion (Fig.5). We find out that although rainfall erosivity factor(R) is higher in southern coastal zone, erosion tends to occur on the slope with lower LS values in northern coastal zone than southern coastal zone. The difference of $\mathrm{K}$ between north and south coastal zone is not obvious. Therefore, the main reason for the erosion difference is the vegetation factor.

In northern coastal zone of China, the rainfall in north China is lower than south China. The temperature in north China is below zero in winter. Vegetation falls during fall and winter season and grows in spring and summer. This leads to worse surface and canopy cover, and vegetation has the weak ability to resist soil erosion. In southern coastal zone of China, average annual rainfall is above $1000 \mathrm{~mm}$ and temperature is relatively high. Vegetation is green during the whole year. This leads to better surface and canopy cover, and vegetation has a high ability to resist soil erosion. This cause the erosion occurs on the slope with higher LS values.

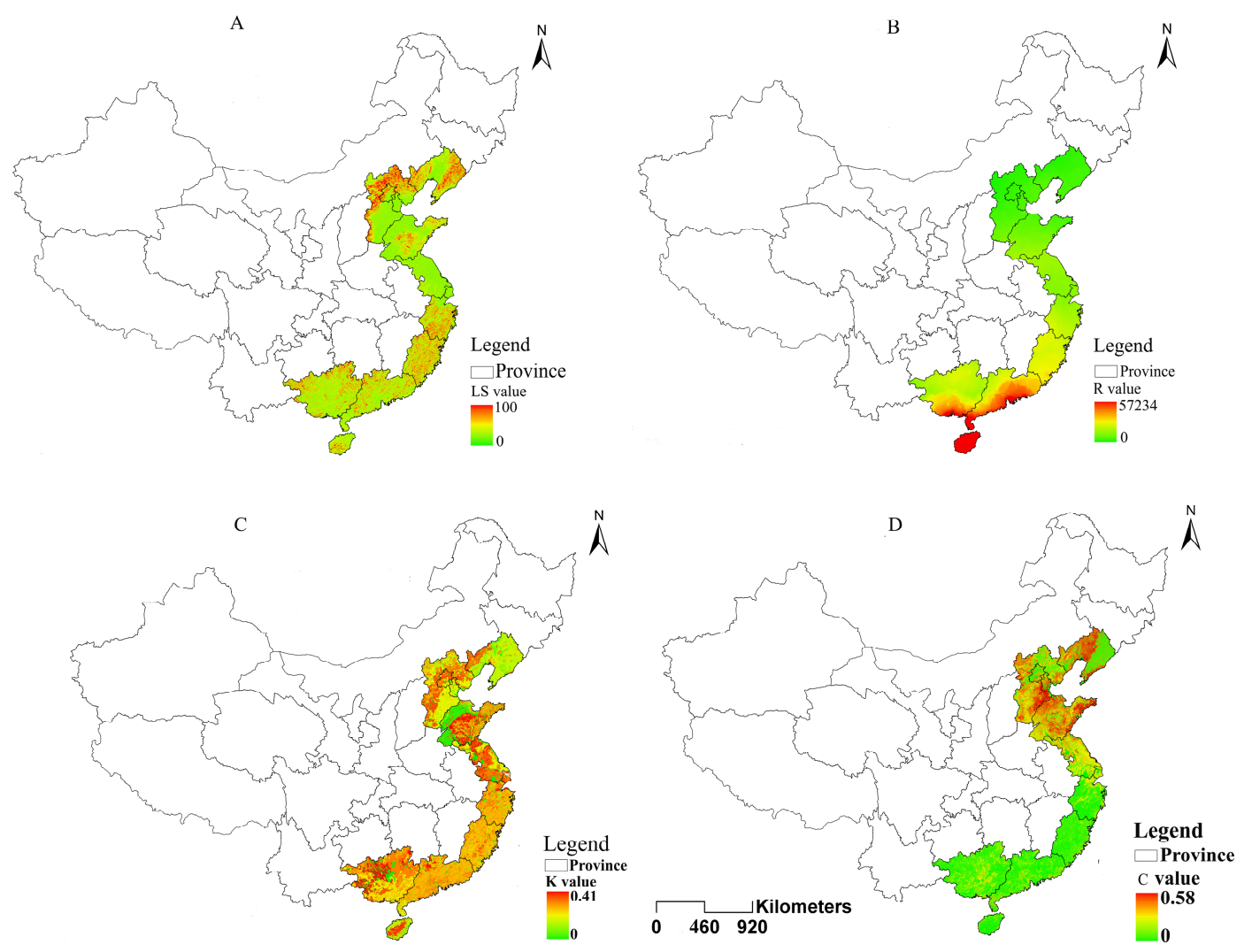

Fig. 5 Factors that cause Erosion: A-LS value, B-R value, C-K value, D-C value

\subsection{Policy and managements on soil erosion}

Although soil erosion is not serious in coastal zone, soil erosion still caused lots of problems in widespread erosion areas. For example, Rongcheng county is located in the area covered by widespread erosion. A fish harbor 
in this county was abandoned due to soil sedimentation. To improve such situations, coastal zone was also included in the Grain-For-Green project by China central government in 2002. Farmland in steep slope was converted to forest or grassland. Owners of farmland were made up according to the area that was converted.

Forest Law was enforced to stimulate the conversion of barren mountains to woodland around the same time. Barren montains owned by collectives or governments were rented to families and were encouraged to green. The period of use right is at least fifty or seventy years and the use right can be transferred and inherited. The certificate of use right was offically distributed to each contractor. The felling of woodland was regulated by local governments according to some planings. The felling woodland needs to be regreened in limited period.

The development speed of economy in coastal zone is very high. China governments set up number of experimental areas of sustainability trying to coordinate the relationship between economic development and land degradation in coastal zone. The objectives of those experimental areas are to reduce farmer's pressure on the ecological systems by repalceing some resource intensive companies with high technique companies. China central government give some priority and funds for such developments every year.

\section{Disscussion}

By result anlysis, we know that coastal zones in Shandong, Hainan and werstern Guangdong are covered by expansive soil erosion. The major erosion class in those areas is moderate erosion class. Severe erosion is occasionaly occurred on some coastal zones. Those expansive erosion leads to large amount of soil runing into seas around those coastal zones.

Population density is very high and area of farmland is very limited in those coastal zones. It is difficulte to preventing soil erosion by simple conversion of farmland to forest or grassland. Since erosion tends to occur on the slopes with lower LS values in norther coastal zone, we should encourage governments get more funds to prevent soil erosion in norther coastal zoen. However, govenments still don't notice this difference. This study also provide a basis for studies on dynamics of coastal land degration and help directions to governments. In future, we should collect more indicators to find out the relationships between coastline changes and soil erosion, and so on.

\section{Conclusions}

RUSLE model was developed with python language according previous studies. LUCC data, DEM, daily rainfal, soil data was input to RUSLE model and spatial distribution of soil erosion in China coastal zone was formed. By spatial analysis in ArcGIS, we found out that soil erosion in China coastal zone is not serious. Expansive soil erosion only occurred in coastal zones in Shandong, Hainan and werstern Guangdong. The major erosion class is moderte erosion class and severe erosion only occasionaly distributed on some land at steep slopes. The driver anlysis shows that erosion tends to occur on the slope with lower LS values in northern coastal zoen than southern coastal zone. Governments have enfored some policy to reduce the extent of soil erosion, but the difference between northern and southern coastal zone is still not noticed. We should encourage governments get more funds to improve vegetation cover in northern coastal zone. This study will provide helpful directions to soil erosion prevention and let limited funds get better results.

\section{Acknowledgements}

The DEM data come from NASA, NDVI data from spot-vegetation(www. spot-vegetation.com), LUCC from Professor Liu Jiyuan and rainfall data from Bureau of China. This study is supported by the National Natural Science Foundation of China (41071278 and 41171334), the Talent Fund of Yantai Institute of Coastal Zone Research, Ecological Innovation and Breeding Project(Y254021031) and the Science and Technology Project of Yantai (2012132). Thanks them all!

Proc. of SPIE Vol. $8869886919-9$ 


\section{References}

[1] Inman D.L., Brush B.M., “The Coastal Challenge,” Science181(4094), 20-32(1973).

[2] Shi C., Hutchinson S.M., Xu S., "Evaluation of coastal zone sustainability: an integrated approach applied in Shanghai Municipality and Chong Ming Island.," Ocean \& Coastal Management 71, 335-344(2004).

[3] Lin T., Xue X.Z., Lu C.Y., "Analysis of coastal wetland changes using the "DPSIR" model: a case study in Xiamen, China," Coastal Management35(2-3),289-303(2007).

[4] Chen J.Y., Chen S.L., "Estuarine and coastal challenges in China," Chinese Journal of Oceanology and Limnology 20(2),174-181(2002).

[5] Liu Jiyuan, Tian Hanqin, Liu Mingliang, Zhuang Dafang, Jerry M. Melillo, Zhang Zengxiang, "China's changing landscape during the 1990s: Large-scale land transformations estimated with satellite data," Geophysical Research Letters 32, 1-5(2005).

[6] Long H.L., Liu Y.S.,Wu X.Q.,Dong G.H., "Spatio-temporal dynamic patterns of farmland and rural settlements in Su-Xi-Chang region: implications for building a new countryside in coastal China," Land Use Policy 26(2),322-333(2009).

[7] Lu Qingshui, Fuyuan Liang, Xiaoli Bi, Rodney Duffy, Zhiping Zhao, "Effects of Urbanization and Industrialization on Agricultural Land Use in Shandong Peninsula,” Ecological Indicator 11(6),1710-1714(2011).

[8] Zhao B., Kreuter U., Li B., Ma Z.J., Chen J.K., Nakagoshi N., "An ecosystem service value assessment of land-use change on Chongming Island, China," Land Use Policy 21(2),139-148(2004).

[9] Shen Y.M., Feng N.H., Zhou Q., Liu Y.M., Chen Z.Y., "The status and its influence of reclamation on Jiangsu coast," Marine Sciences10,39-43(2006).( In Chinese)

[10] Bi, X.L., Wang, B., Lu, Q.S., "Fragmentation effects of oil wells and roads on the Yellow River Delta, North China," Ocean \& Coastal Management54(3),256-264(2011).

[11] Sterr H., "Assessment of Vulnerability and Adaptation to Sea-Level Rise for the Coastal Zone of Germany," Journal of Coastal Research 24(2), 380-393(2008).

[12] Dolan A.H., Walker I.J., "Understanding vulnerability of coastal communities to climate change related risks," Journal of Coastal Reserch 39,1316-1323(2006).

[13] Ni H., "Status and Development Perspective of the Coastal Shelterbelt in Zhejiang Province," Bulletin of Science and Technology 16(3), 201-205(2000).

[14] Wu X.Q., Gao M., Wang D.,Wang Y.,Lu Q.S.,Zhang Z.D., 2012. "Framework and practice of integrated coastal zone management in Shandong province, China," Ocean\&CoastalManagement 69,58-67(2012).

[15] Zhang W.B., Xie Y., Liu B.Y., "Methods for Calculating Rainfall Erosivity with Daily Rainfall," Geographical Research 22(6), 705-711(2002). ( in Chinese)

[16] Xie Y., Liu B.Y., Zhang W.B., "Standards for Erosivity Rainfall," Journal of Soil and Water Conservation 14(4), 6-11(2000).

[17] Chinese Soil Taxonomy Research Group, Institute of Soil Science, Academia Sinica and Cooperative Research Group on Chinese Soil Taxonomy, 1995. [Chinese soil taxonomy (revised proposal)], China Agricultural Science and Technology Press, Beijing.( in Chinese)

[18] Wischmeier W.H., Smith D.D., "Predicting Rainfall Erosion Losses : A Guide to Conservation Planning," U. S. Dep. Agric. Agric. Handb. No.537(1978).

[19] Renard K.G., Foser G.R., Weesies G.A., et al., "Predicting soil erosion by water: A guide to conservation planning 
with the revised universal soil loss equation (RUSLE)," Agriculture Handbook No. 703. U. S. Department of Agriculture. Washington, DC.(1997).

[20] Van Remortel, R., Hamilton M., Hickey R.,2001. Estimating the LS factor for RUSLE through iterative slope length processing of DEM elevation data. Cartography. 30(1), 27 - 35.

[21] Liu B.Y., Bi X.G.,Fu S.H., 2010. [Beijing Soil Loss Formula], Science Press, Beijing. ( in Chinese)

[22] Xu Yueqing, Luo Ding, Peng Jian, "Land use change and soil erosion in the Maotiao River watershed of Guizhou Province,” Journal of Geographical Sciences 21(6), 1138-1152(2011).

[23] The Ministry of Water Resources of China, [Standards of classification and gradation of soil erosion], Beijing(2008). ( in Chinese) 